\title{
NERVE ENTRAPMENT IN THE OSSEOAPONEUROTIC TUNNEL MIMICKING STRUTHER'S LIGAMENT ASSOCIATED WITH SUPER- FICIAL BRACHIAL ARTERY: AN EMBRYOLOGICAL ERROR
}

\author{
Geeta Anasuya. D *1, T. Jones Eben Raj ${ }^{2}$, Sheela Grace Jeevamani ${ }^{3}$. \\ ${ }^{* 1}$ Assistant Professor, Dept of Anatomy, Karpagam Faculty of Medical Sciences and Research, \\ Coimbatore, Tamil Nadu, India. \\ ${ }^{2}$ Tutor, Dept of Anatomy, Karpagam Faculty of Medical Sciences and Research, Coimbatore, Tamil \\ Nadu, India. \\ ${ }^{3}$ Professor \& HOD, Dept of Anatomy, Karpagam Faculty of Medical Sciences and Research, \\ Coimbatore, India.
}

\section{ABSTRACT}

Introduction: Coracobrachialis muscle is well known for its morphological variations. Anatomical variation of coracobrachialis near its insertion can cause compression of median nerve and brachial artery by mimicking struther's ligament. Our aim of the study was to examine and record the variations in origin and insertion of coracobrachialis muscle and to see their relationship with the median nerve and brachial artery.

Methodology: During routine dissection for undergraduate students in KFMSR, 64 upper limbs were dissected and observed for any variations in origin and insertion of Coracobrachialis muscle.

Results: Of the 64 upper limbs dissected, we noted that in one cadaver, there were two heads of origin for coracobrachialis muscle and there was also a variation in the insertion as abnormal slips, which were attached to antebrachial fascia. The blood supply to this muscle was from the muscular branches of superficial brachial artery.

Conclusion: The knowledge of this type of variations is important for surgeons, radiologists, neurologists and physiotherapists for proper decision making during surgical considerations and injuries around elbow joint. Neurovascular structures like median nerve and superficial brachial artery may be compressed by the abnormal slips of coracobrachialis close to insertion.

KEY WORDS: Variation of coracobrachialis, Abnormal slips, compression of Median nerve, Superficial brachial artery.

Address for Correspondence: Dr Geeta Anasuya MD, Assistant Professor, Dept of Anatomy, Karpagam Faculty of Medical Sciences and Research, Coimbatore- 32, India. Ph: + 919677982797 E-Mail: geetagee1@gmail.com

Access this Article online Quick Response code

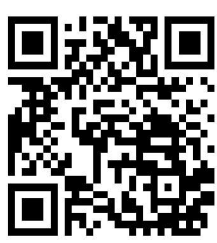

DOI: $10.16965 /$ ijar.2017.498

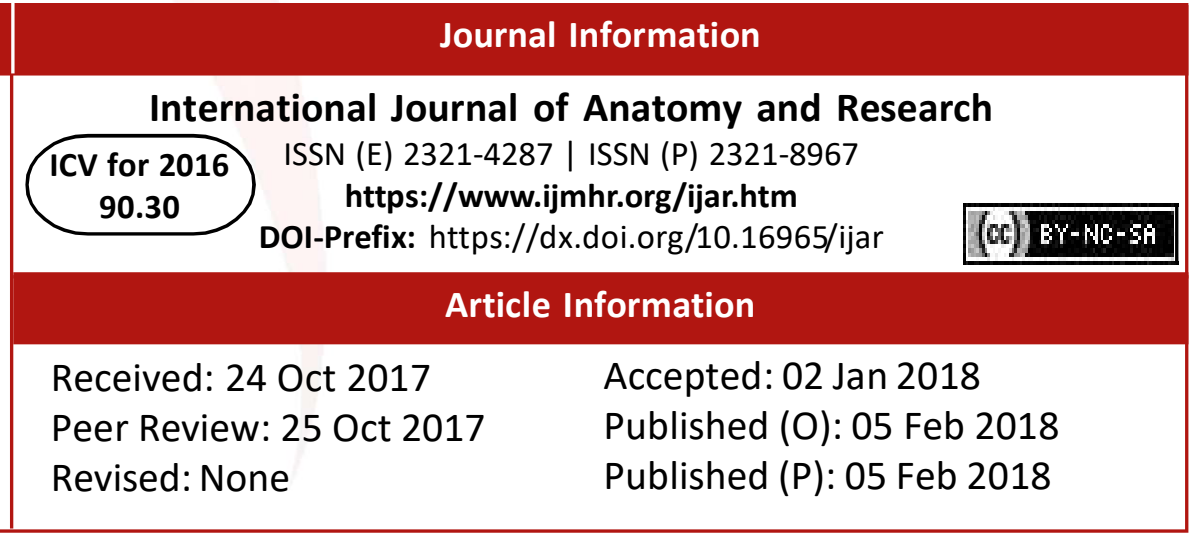

\section{INTRODUCTION}

Coracobrachialis (CB), a functionally unimportant muscle, is located in the anterior compartment of arm [1]. It usually arises from the tip of coracoid process along with tendon of short head of biceps brachii (SHB) and also by muscular fibres from the proximal $10 \mathrm{~cm}$ of this tendon. It ends on an impression, $3-5 \mathrm{~cm}$ in length, midway along the medial border of the shaft of humerus between the attachments of 
triceps and brachialis. It forms an inconspicuous rounded ridge on the upper medial side of the arm. Third part of axillary artery and proximal parts of median and musculocutaneous nerves lie medial to it. Biceps and brachialis lie lateral to it [2]. The musculocutaneous nerve $(\mathrm{C} 5, \mathrm{C} 6, \mathrm{C} 7)$, branch of the lateral cord of brachial plexus usually supplies the muscle [1,2]. It usually flexes the arm forward and medially especially from brachial extension [2]. Morphologically, it represents the adductor group of muscles in the arm but such function later became insignificant during the process of evolution.

Coracobrachialis is known to show different types of variations [3-10]. Variations in insertion include accessory slips that attach to the lesser tubercle, medial intermuscular septum or medial supracondylar ridge $[3,8]$. It is tricipital in origin in some mammals. The upper two heads are fused to take origin from the coracoid process and encloses the musculo cutaneous nerve between them. The lower head is usually suppressed in man, and is sometimes represented by a fibrous band called the "Ligament of Struthers" or "Internal brachial ligament" which extends from supratrochlear spur to medial epicondyle. If this is present, median nerve or brachial artery or both may pass beneath it and might compress them producing vascular spasm or median nerve palsy [6-17].

The axillary artery becomes the brachial artery at the lower border of the tendon of the teres major muscle. A superficial brachial artery is defined as a brachial artery which has a superficial course to the median nerve, where as a deep brachial artery corresponds to the brachial artery, with its normal course behind the median nerve [18-20]. The variability of this arterial pattern may be due to the failure of regression of some paths of the embryonic arterial trunks [21]. Knowledge of these variations is very essential for surgeons to treat the neurovascular compression syndromes during orthopedic and reconstructive procedures.

\section{MATERIALS AND METHODS}

The present study was done during routine dissection on 64 upper limbs of 32 embalmed cadavers for first year MBBS students in KFMSR,
Coimbatore, India. Dissection of Coracobrachialis muscle was done according to the instructions by Cunningham's manual of practical anatomy in both upper limbs (right and left). The study was conducted to see for variations in origin and insertion from the muscle. Also the relationship of median nerve and brachial artery with variations was observed. Measurements of the muscle (fleshy part, tendon and aponeurotic part) was done using digital calipers and recorded in millimeters. Later, the measurements were converted to centimeters for ease.

\section{RESULTS}

The study has given the idea for the presence of two heads of origin of the Coracobrachialis muscle. The variation in insertion and relationship of the muscle with musculocutaneous nerve also gives the idea that the $C B$ is a complex muscle.

\section{Observations:}

Among 64 arms, the following variations were noted in the right upper limb of a female cadaver.

Variations in Origin of Coracobrachialis:( Fig: 1) Coracobrachialis muscle was formed of two heads.

Superficial (anterior) head: It had a fleshy belly and attached to most of the medial border of tendon of short head of biceps brachii muscle. In the lower one-third, the fleshy fibres became tendo aponeurotic.

Deep (posterior) head: Origin of this head was fleshy and tendinous and was seen deep to the tendon of SHB. It was attached to coracoid process of scapula, adjoining part of the lateral border of tendon of short head of biceps and finally was seen along the medial aspect of superficial head of CB. In the lower one-third, it became tendo aponeurotic.

\section{Variations in insertion : ( Fig:2, 2a )}

Superficial head of $\mathrm{CB}$ was seen passing along the medial aspect of SHB, then became tendinous and finally got inserted as aponeurotic expansion (AS) into the antebrachial fascia. Near the inserting fibres, median nerve and superficial brachial artery were seen passing beneath the abnormal slip of aponeurotic expansion. 
Deep head of $C B$ was seen passing along the medial aspect of superficial head, and on reaching the middle of the shaft of humerus, got attached to the medial intermediate septum as a tendon. After that tendinous insertion, it continued downwards as abnormal slip of osseoaponeurotic expansion (AS1) and got inserted to the antebrachial fascia and posterior surface of ulna.

The inserting fibres coming from both superficial and deep heads are interconnected by osseoaponeurotic fibres. (Fig: $\mathbf{3}$ )

There was an aponeurotic band measuring 2 / $0.5 \mathrm{~cm}$ extending from the tendon of short head of biceps to AS1. (Fig: 3a)

Relationship of Musculocutaneous nerve and Coracobrachialis muscle: (Fig: 5)

Musculocutaneous nerve after arising from lateral cord of brachial plexus was seen piercing the deep head of CB. Later it passed between deep and superficial heads of Coracobrachialis and then continued downwards as lateral cutaneous nerve of forearm.

It also gave a separate branch to superficial head of CB.

In the same upper limb, there was higher division of axillar artery into superficial and deep brachial artery $6 \mathrm{cms}$ above the lower border of teres major. Superficial brachial artery was seen passing downwards in the anterior aspect of the arm from lateral to medial side. It gave muscular branches to superficial head of CB, SHB and brachialis. Later, it passed beneath the abnormal slip of inserting fibres coming from superficial head of CB. In the cubital fossa it was seen lateral to median nerve. At the neck of radius, was seen dividing into superficial radial and superficial ulnar artery. Deep Brachial Artery supplied the deep head of CB. (Fig: 6, 6a).

Fig. 1: CB - Coracobrachialis, SHB - Short head of Biceps.

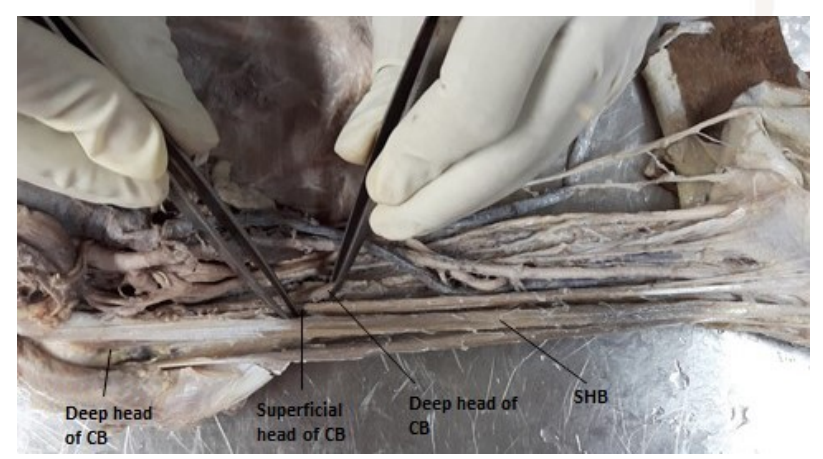

Int J Anat Res 2018, 6(1.2):4884-89. ISSN 2321-4287
Fig. 2: AS. Aponeurotic expansion of superficial head (Abnormal slip). AS1. Aponeurotic expansion of deep head (Abnormal slip 1). C. Antebrachial fascia D. Tendon part.

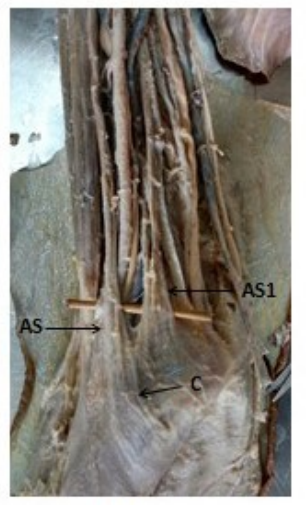

Fig: 2

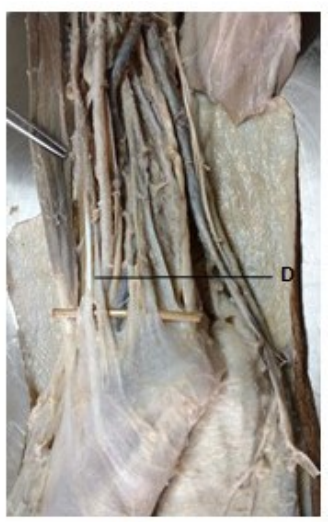

Fig: 2a
Fig. 3: Arrow shows the interconnecting osseoaponeurotic expansion.

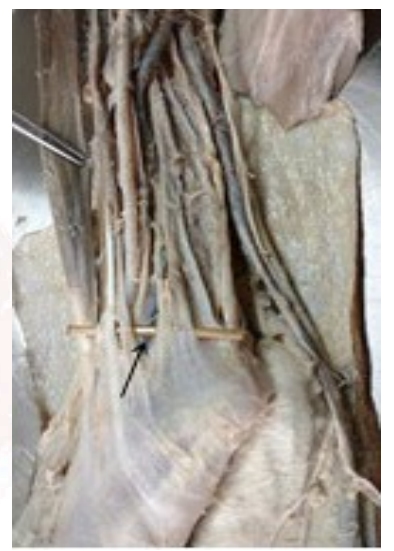

Fig. 3a: 1. Tendon of short head of biceps 2. Abnormal slip of insertion from superficial head of coracobrachialis. 3. Aponeurotic band extending from the tendon of short head of biceps to abnormal slip of superficial head of coracobrachialis muscle.

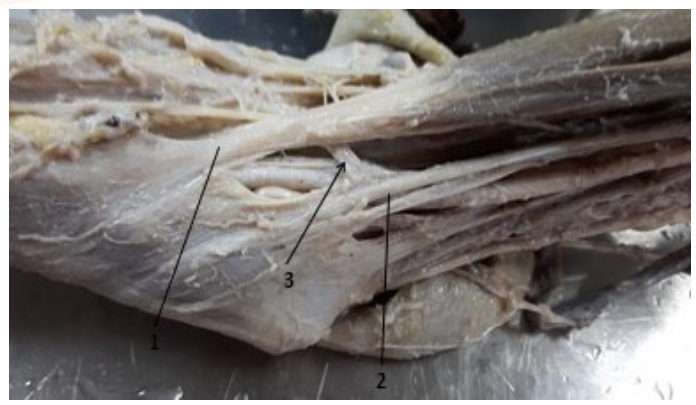

Fig. 4: Showing the measurement of the upper part of tendon of superficial head of coracobrachialis using digital calipers.

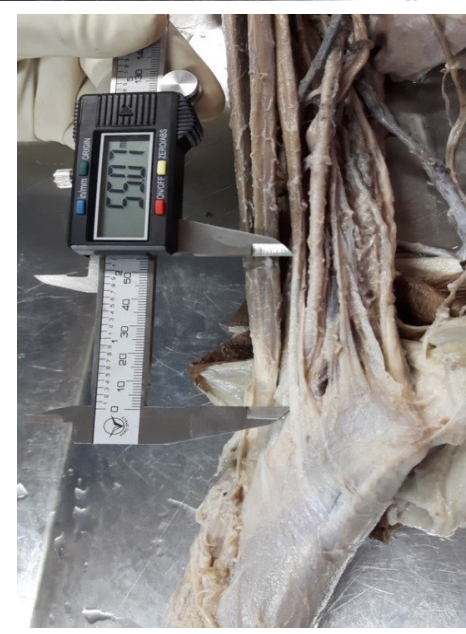


Fig. 5 \& 5a: $(1,2,3,4,5)$. Showing the musculocutaneous nerve(MCN), piercing $B$ and then passing between $B$ and $A$ ,later continuing downwards as lateral cutaneous nerve of forearm. B. Deep head of CB. A. Superficial head of CB.
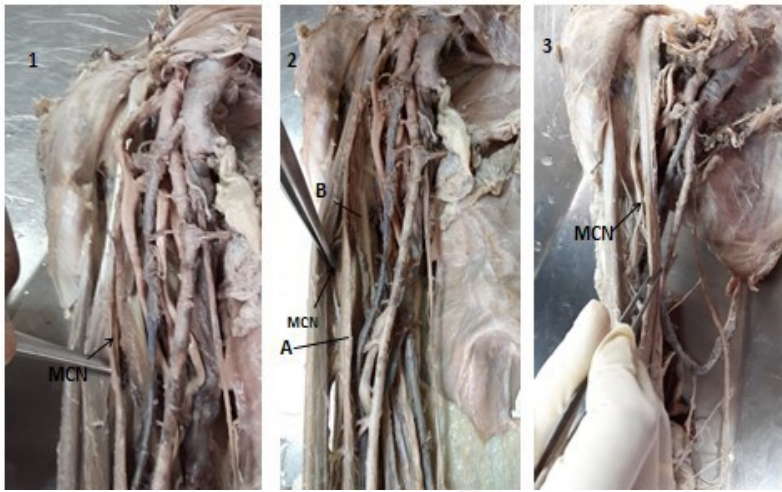

Fig. 6: A. Superficial Brachial artery B. Median nerve and $\mathrm{C}$. Brachial vein passing beneath the osseoaponeurotic expansion from superficial head of $C B$.

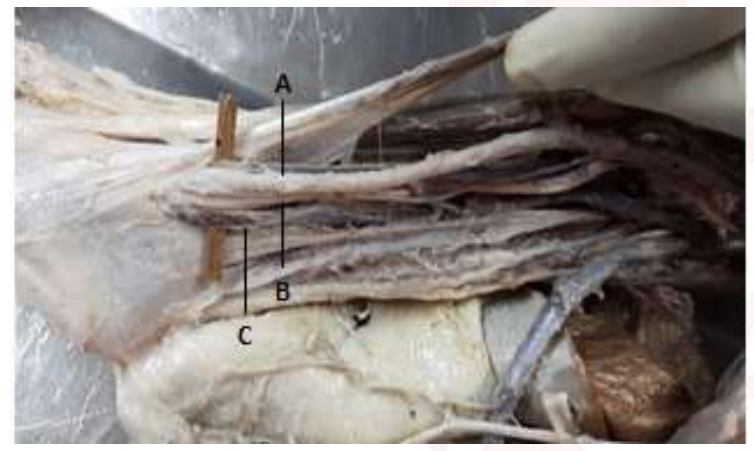

Table 1: Showing measurements of Coracobrachialis.

\begin{tabular}{|c|c|c|c|c|}
\hline $\mathbf{1}$ & $\begin{array}{c}\text { Superficial head of } \\
\text { Coracobrachialis (CB) Total } \\
\text { length- 30cm }\end{array}$ & $\begin{array}{c}\text { Total length of tendon- } 12 \mathrm{~cm} \\
\text { Upper part }-5.5 \mathrm{~cm} \mathrm{(Fig:4)}\end{array}$ & Fleshybelly-14cm & Aponeurotic part- 4cm \\
\hline $\mathbf{2}$ & $\begin{array}{c}\text { Deep head } \\
\text { Total length- 27cm }\end{array}$ & Tendon- $7.6 \mathrm{~cm}$ & Fleshybelly-12cm & Aponeurotic part- $7.2 \mathrm{~cm}$ \\
\hline $\mathbf{3}$ & $\begin{array}{c}\text { Breadth of aponeurotic part: } \\
\text { from medial epicondyle to AS } \\
4.28 \mathrm{~cm}\end{array}$ & $\begin{array}{c}\text { From medial epicondyle to } \\
\text { the AS1-3.5cm }\end{array}$ & $\begin{array}{c}\text { gap between two } \\
\text { aponeurotic insertions- } \\
0.5 \mathrm{~cm}\end{array}$ & AS $-0.28 \mathrm{~cm}$ \\
\hline
\end{tabular}

\section{DISCUSSION}

It is common that variations in origin, insertion and nerve supply of Coracobrachialis muscle do occur. The abnormal tendoaponeurotic slips extending from Coracobrachialis muscle may cause compression of the median nerve and brachial artery. Various studies have described the compression of median nerve and brachial artery with Anamolous muscles $[4,5,7]$. The accessory slips of $C B$ are used as transposition flap in deformities of infraclavicular and axillary areas and in post mastectomy reconstruction [11].

Surwase R. Gopalrao et al in their study reported an anomalous coracobrachialis muscle having
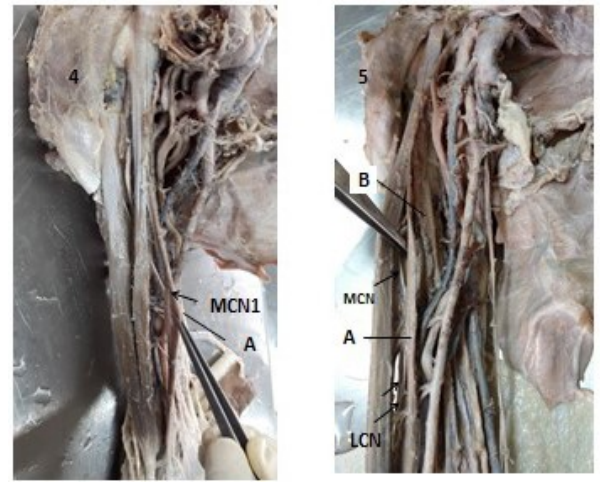

Fig. 6a: Superficial brachial artery (SBA) passing beneath the aponeurosis of superficial head of coracobrachialis.

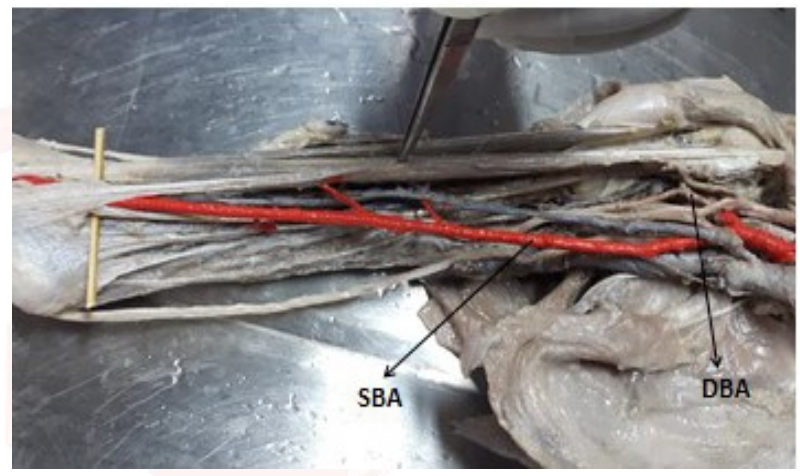

proximal attachment from the fibrous band of medial intermuscular septum of arm and distal attachment was to the medial epicondyle of humerus and to the antebrachial fascia [17]. From the clinical aspect, the muscle insertion into the medial epicondyle and antebrachial fascia makes the anterior compartment narrow during contraction of coracobrachialis muscle and could result in proximal median neuropathic symptoms and brachial artery compression. In our study, abnormal slip (AS) from the superficial head of CB only covered the median nerve and brachial artery, whereas the abnormal slip (AS1) from deep head became continuous with antebrachial fascia without covering the median 
nerve and brachial artery.

Morphological variations in origin and insertion of muscle could be explained in terms of comparative anatomy. During the changes in locomotion pattern from reptiles to mammals, the adductor shoulder muscles became greatly reduced into the Coracobrachialis muscle [8]. Wood found that $C B$ muscle in small animals has three heads. They are Coracobrachialis brevis (profundus) which is inserted into humerus superior to the tendon of lattissimus dorsi , Coracobrachialis medius (proprius), which is inserted into the humerus inferior to the tendon of lattissimus dorsi and Coracobrachialis longus (superficialis) or Wood's muscle which extends inferiorly on the shaft of humerus bridging the median nerve and brachial artery $[1,3]$.

In human beings, two heads have fused, trapping the musculocutaneous nerve between them, while the third head has become suppressed [1]. In our study, there are two heads for coracobrachialis with variable degree of development, that could be attributed to the varied degrees of fusion of its ancestral two heads [Fig:1]. Ray et al [13] found that CB originated from the coracoid process and then divided into two heads. The muscular head inserted into antero medial part of the middle of humeral shaft while musculo aponeurotic head inserted into medial intermuscular septum forming a tunnel for the passage of superficial brachial artery. Our study also showed variations in insertion from both superficial and deep heads. The accessory slip from superficial head formed as tendon measuring $12 \mathrm{~cm}$ and later became aponeurosis to pass in front of median nerve and superficial brachial artery and finally attached to the antebrachial fascia. Near the inserting fibres from the deep head, there was presence of ligamentous structure that extended up to medial condyle measuring $14.8 \mathrm{~cm}$ in length mimicking Struthers ligament. Later, this ligamentous structure became aponeurotic and continued with fascia on posterior surface of ulna. [Fig: 2-4]

Padma Varlekar et al [12] reported an additional slip of insertion, beside usual insertion which consists of fibres passing downwards and medially in front of median nerve and brachial artery to blend with the deep fascia on the medial aspect of arm. This study also reported abnormal slips extending downwards and medially to the medial epicondyle of the humerus without covering the median nerve and brachial artery. In a similar way, Maitrayee Mondal et al [15] reported an additional slip of CB muscle about $11 \mathrm{~cm}$ in length being inserted to distal part of medial intermuscular septum bridging the median nerve and brachial artery.

Ashwini M Mutalik [14] found the normal origin of $C B$ but near to the insertion, there was a ligamentous structure (about $15 \mathrm{~cm}$ in length), extending upto the medial epicondyle. The median nerve and brachial artery were seen passing superficial to this ligamentous structure.

Developmental basis: The morphological variations in the origin of coracobrachialis may be explained on the basis of the embryogenesis of the muscles of the arm. The muscles of the upper limb differentiate in situ from the limb bud mesenchyme of lateral plate mesoderm. The muscle primordia within the different layers of the arm at a certain stage of development, fuse to form a single muscle mass, thereafter, some muscle primordial disappear through cell death. Failure of muscle primordial to disappear during embryologic development may account for the presence of the accessory insertion of coracobrachialis muscle [16]. Variations of muscle may be a result of altered molecular interaction between the mesenchymal cells $[19,20]$.

\section{CONCLUSION}

The coracobrachialis is a complex muscle showing double heads of origin and also accessory slips of insertion. The knowledge of these variations is very essential as they can be confused with tumors in $\mathrm{CT}$ and MRI scans. Compression of nerve and vessels beneath the tunnel of accessory slips can lead to ischemic changes of forearm and also wasting of muscles of the anterior compartment of forearm. The observations of the present study may be useful for surgeons as well as radiologists.

\section{Conflicts of Interests: None}

\section{REFERENCES}

[1]. MC Minn RMH. Last's Anatomy: Regional and Applied. 8th ed., Edinburgh: Churchill Livingstone; 1990. pp.79. 
[2]. Williams PL, Bannister LH, Berry MM, Collins P, Dyson M, Dussek JE et al. Muscle. In Gray's Anatomy 38th Ed. Edinburg: Churchill Livingstone; 1995: $p$ 842. 626, 837.

[3]. Wood J. On human muscular variations and their relation to comparative anatomy . J Anat Physiol. 1867;1:44-59.

[4]. El-Naggar M. A study on the morphology of the coracobrachialis muscle and its relationship with the musculocutaneous nerve. Folia Morphol (Warsz). 2001; 60:217-224.

[5]. Mustafa M, El-Naggar and Samar Al-saggif. Variant of coracobrachialis Muscle with a tunnel for the median nerve and brachial artery: a case report. Clinical Anat. 2004;17:139-43.

[6]. Datta A.K. The arm. In. Essentials of Human Anatomy, Superior and Inferior extremities. Part-III 4th Edition., Kolkatta; Current Books International; 2004.pp.56-59.

[7]. Vincent Rodrigues, Satheesha Nayak, Somayaji Nagabhooshana and Venkata Ramana Vollala. Median nerve and brachial artery entrapment in the tendinous arch of coracobrachialis muscle. IJAV. 2008;1:28-29.

[8]. Howell AB, Straus WL. The brachial flexor muscles in primates. Proceedings of the United States National Museum. 1931;80:1-31.

[9]. Potu BK, Rao MS, Nayak SR, Vollala VR, Mandaua AK, Thomas $\mathrm{H}$ : Variant insertion of coracobrachialis muscle in a South Karnataka Cadaver, cases Journal 2008;1:291.

[10]. Kumar N, Shetty SD, Somayajl SN, Nayak SB: Presence of accessory coracobrachialis and its clinical importance - A case report, Int. J. Anat. Var. (IJAV) 2012;5:27-28.

[11]. Kopuz C, Içten N, Yildirim M. A rare accessory coracobrachialis muscle: a review of the literature. Surg Radiol Anat. 2003 Feb; 24(6):406-10.

[12]. Varlekar PD, Chavda HS, Khatri CR, Saiyad SS, Nagar $S$, Kubavat $D$. A study on variation in the insertion of Coracobrachialis muscle and its clinical importance. Int J Med Sci Public Health 2014;3:42-45.

[13]. Ray B, Rai A. L, Roy T. S.: Unusual insertion of coracobrachialis muscle to the brachial fascia associated with high division with brachial artery. Clin. Anat, 2004;17:672-676.
[14]. Ashwini M. Mutalik. Variations in the Coracobrachialis and Brachialis of Arm. IJSR. Sep 2014;3(9); 2277-8179.

[15].Maitrayee Mondal, Pallab Kumar Saha, Sayongdeepa Roy, Aradhana Sanga, Champak Kumar Dey, Sudheshna Majumdar. Accessory slip of coracobrachialis muscle - a case report. Indian Journal of Basic and Applied Medical Research; December 2015;5(1):565-567.

[16]. Guha R, Satyanarayana N, Reddy CK, Jayasri N, Nitin V, Praveen G, Sunitha P, Datta AK: Variant insertion of coracobrachialis muscle - morphological significance, embryological basis and clinical importance, JCMS-NEPAL.2010;6(2):42-46.

[17]. Surwase R.Gopalrao, Lakshmi Rajgopal. An anomalous coracobrachialis muscle-a case report Int J Cur Res Rev, Sep. 2013;05(17):112-115.

[18]. Tohno Y, Tohno S, Azuma C, Kido K, Moriwake Y. Superficial brachial artery continuing into the forearm as the radial artery. J Nara Med Assoc. 2005;56:189-193.

[19]. Taylor GI, Cichowitz A, Ang SG, Seneviratne S, Ashton $\mathrm{M}$ : Comparative anatomical study of the gracilis and coracobrachialis muscles: implications for facial reanimation. Plast Reconstr Surg2003; 112:20-30.

[20]. Keith L Moore and Persuad T.V.N, The Muscular system. The Developing Human clinically oriented Embryology. 2009; $8^{\text {th }}$ edition: P 358-362. Elsevier.

[21]. Neelamjit Kaur, Patnaik V. V. Gopichand, Rajan Kumar Singla . Bilateral superficial brachial artery - a case report. IJAV. 2011;4:207-210.

[22]. Keith L Moore and T.V.N. Persuad, The Muscular system. The Developing Human clinically oriented Embryology. $7^{\text {th }}$ edition: P 406. Elsevier.

How to cite this article:

Geeta Anasuya. D, T. Jones Eben Raj, Sheela Grace Jeevamani. NERVE

ENTRAPMENT IN THE OSSEOAPONEUROTIC TUNNEL MIMICKING STRUTHER'S LIGAMENT ASSOCIATED WITH SUPERFICIAL BRACHIAL ARTERY: AN EMBRYOLOGICAL ERROR. Int J Anat Res 2018;6(1.2):48844889. DOI: $10.16965 /$ ijar.2017.489 